\title{
Governança pública: análise da alienação de bens móveis com base nas recomendações da IFAC no IFPB
}

\author{
Camila Martins de Freitas ${ }^{1}$ \\ Dimmitre Morant Vieira Gonçalves Pereira ${ }^{2}$ \\ José Jassuipe da Silva Morais ${ }^{2}$
}

${ }^{1}$ Instituto Federal de Educação, Ciência e Tecnologia da Paraíba (IFPB), Campina Grande - PB, Brasil ${ }^{2}$ Universidade Federal da Paraíba (UFPB), Mamanguape - PB, Brasil

A administração pública brasileira busca mudanças por meio das suas reformas, tentando diminuir as práticas que inibem seu bom funcionamento. Dessa forma, o modelo de administração gerencialista vivenciado atualmente buscou trazer os instrumentos de gestão que demonstraram êxito no âmbito privado ao serem utilizados na administração pública, a saber, a governança. Neste viés, o presente artigo busca analisar o nível de aderência do processo de alienação de bens móveis às práticas de governança pública elencadas pela International Federation Accounting Committee (IFAC). Trata-se de um estudo de caso de abordagem qualitativa, utilizando-se da técnica de pesquisa de triangulação de dados a partir de fontes bibliográficas, documentais e da observação direta, realizado no âmbito do Instituto Federal da Paraíba, campus Campina Grande. Somados à observação direta, os dados foram coletados em legislações, normativas internas, relatórios internos, regulamentos e edital, nos quais se fez um estudo acerca da governança pública trazida nas recomendações da IFAC. Os resultados do estudo apontaram que o IFPB Campus Campina Grande cumpre parcialmente as exigências da IFAC em seu processo de desfazimento, atendendo satisfatoriamente às dimensões padrões de comportamento e estruturas e processos organizacionais e necessitando de melhorias nas dimensões controle e relatórios externos. Assim, apesar de atender a alguns pontos específicos, verifica-se a necessidade de ampliar a aderência das práticas de desfazimento de tais categorias.

Palavras-chave: governança pública, alienação de bens, IFPB 


\section{Gobernanza pública: análisis de la alienación de bienes muebles basados en las recomendaciones de IFAC en IFPB}

La Administración Pública brasileña busca cambios a través de sus reformas, tratando de reducir las prácticas que inhiben su buen funcionamiento. Así, el modelo de gestión gerencial que se vive hoy busca acercar los instrumentos de gestión que han tenido éxito en el ámbito privado para ser utilizados en la Administración Pública, a saber, la gobernanza. En esta línea, este artículo busca analizar el nivel de adherencia del proceso de enajenación de bienes muebles a las prácticas de gobierno público enumeradas por el Comité de Contabilidad de la Federación Internacional (IFAC). Se trata de un estudio de caso con abordaje cualitativo, utilizando la técnica de investigación de triangulación de datos de fuentes bibliográficas, documentales y de observación directa, realizado en el ámbito del Instituto Federal de Paraíba, campus Campina Grande. Los datos fueron recogidos en leyes, reglamentos internos, informes internos, reglamentos y aviso público, en los que se realizó un estudio sobre la gobernanza pública planteada en las recomendaciones de la IFAC. Los resultados del estudio mostraron que la IFPB - Campus Campina Grande cumple parcialmente con los requisitos de la IFAC en su proceso de desmantelamiento, cumpliendo satisfactoriamente con las dimensiones estándar de comportamiento y estructuras y procesos organizacionales y requiriendo mejoras en las dimensiones de control y reporte externo. Así, a pesar de cumplir con algunos puntos específicos, existe la necesidad de incrementar la adherencia de las prácticas de deshacer de tales categorías.

Palabras clave: gobernanza pública, alienación de bienes, IFPB

\section{Public Governance: analyze the elimination of furniture blessings based on the IFAC recommendations in the IFPB}

The Brazilian Public Administration seeks changes through its reforms, trying to reduce the practices that inhibit its good functioning. Thus, the model of managerial administration experienced today seeks to bring the management instruments that have proved successful in the private sphere to be used in Public Administration, namely, governance. In this manner, this article seeks to analyze the level of adherence of the process of alienation of movable assets to public governance practices listed by the International Federation Accounting Committee (IFAC). This is a case study with a qualitative approach, using the data triangulation research technique from bibliographic, documentary and direct observation sources, carried out within the scope of the Federal Institute of Paraíba, Campina Grande campus. The data was collected in laws, internal regulations, internal reports, regulations and public notice, in where a study was made about public governance brought up in the IFAC recommendations. The results of the study showed that the IFPB - Campus Campina Grande partially met the requirements of IFAC in its undoing process, satisfactorily meeting the standard dimensions of behavior and organizational structures and processes and requiring improvements in the dimensions of control and external reporting. Thus, despite meeting some specific points, there is a need to increase the adherence of undoing practices to such categories.

Keywords: public governance, disposal of assets, IFPB 


\section{Introdução}

No decurso do tempo, a gestão administrativa pública vem sofrendo paulatinas modificações. Tais mudanças estão direcionadas para a responsabilização dos entes em prestar serviços de qualidade, respaldados na integridade e transparência das suas ações. Neste sentido, a governança pública emerge como um instrumento para a melhoria do desempenho no âmbito das instituições públicas.

No Brasil, há um esforço para implementá-las nas práticas administrativas, desenhado na edição de normativas, a exemplo do Decreto $n^{\circ} 9.203$, de 22 de novembro de 2017, que dispõe sobre a política de governança da administração pública federal direta, autárquica e fundacional, editado pelo Decreto $n^{\circ}$ 9.203, de 8 de julho de 2019.

Entre os entes estatais que possuem o papel de auxiliar a sociedade e de buscar por padrões de excelência na execução de suas atividades, encontram-se as Instituições Federais de Educação Superior (IFES).

Neste escopo, o presente artigo objetiva analisar a aderência do processo de alienação pública dos bens móveis permanentes inservíveis do IFPB - campus Campina Grande (desde sua fundação, no ano de 2007, a 2019) às recomendações de boa governança pública elencadas pela International Federation Accounting Committee (IFAC).

De vertente qualitativa, a pesquisa trata-se de um estudo de caso, realizado a partir da seleção de três fontes distintas de evidências elencadas por Yin (2005), a saber: documentação, registros em arquivos e observação direta ${ }^{1}$.

Dessa maneira, o estudo se debruçou nas seguintes fontes: legislações e demais normativas externas (legislações patrimoniais, legislações referentes às IFES), normativas internas (Regimento Interno, manuais internos de Patrimônio e Contabilidade, Relatórios de Gestão, processo de Desfazimento, Editais de desfazimento, registros em sistemas informatizados patrimoniais e sistema financeiro, atas de reuniões da comissão de desfazimento, relatórios/registros de controle e de auditoria). Tais documentos remetem ao período de 2007 a 2019.

Também foi utilizada a observação a reuniões e trabalhos executados pela Comissão de Desfazimento, a rotinas do setor patrimonial, ao relacionamento entre

\footnotetext{
${ }^{1}$ Yin (2005) versa sobre as peculiaridades de cada fonte de evidência, destacando os pontos fortes e fracos de cada uma.
} 
servidores, ao ambiente físico de guarda de materiais e demais condições materiais relacionadas a execução do processo de alienação.

A técnica de análise utilizada foi a triangulação de dados, em que as fontes citadas foram confrontadas entre si, desenvolvendo linhas convergentes de investigação, fazendo com que as distintas informações possibilitassem conclusões muito mais acuradas, seguindo um modelo corroborativo de pesquisa no estudo de caso (YIN, 2005, p. 126).

O artigo é dividido em quatro seções onde, no primeiro momento, a introdução aborda os contornos gerais da pesquisa. Em seguida, embasa-se teoricamente a pesquisa, tendo como fulcro principal as recomendações trazidas pela IFAC acerca da boa governança pública. Na sequência, cada dimensão sugerida na proposição teórica é aprofundada, correlacionando-a à estrutura do IFPB. Por fim, à luz das proposições traçadas, é feita uma análise da aderência do processo de desfazimento no IFPB campus Campina Grande às sugestões elencadas pela IFAC.

Logo, os resultados alcançados nesta pesquisa visam servir como aporte para o IFPB - campus Campina Grande e demais IES na execução dos próximos desfazimentos, a fim de torná-los mais efetivos no que diz respeito ao atendimento às recomendações de governança pública trazidas sob a ótica da IFAC.

\section{Recomendações de governança no setor público}

Acerca das categorias que alicerçam a pesquisa, no que concerne à alienação, esta refere-se a um termo jurídico, de aspecto geral, utilizada para denominar o ato administrativo em que haja transferência do domínio do objeto para outra pessoa, podendo manifestar-se na forma de permuta, venda ou doação (CoUTiNHO, 2004).

Quanto à IFAC, constitui-se em uma federação internacional composta por várias instituições que representam contadores que trabalham no setor privado, no público e nas universidades. Conta com o Public Sector Committee (PSC) em sua constituição, um comitê que possui o papel de elaborar programas de aperfeiçoamento da gestão financeira e contábil no setor público, por meio da implementação de padrões, documentos e estudos direcionados para esta área (SCARPIN; SÖTHE; KREUZBERG, 2012).

Já a governança pública é compreendida, em linhas gerais, como a competência do Estado de fazer com que as decisões tomadas se transformem em realidade, de maneira 
efetiva e eficiente ${ }^{2}$. Um Estado possui uma governança forte quando tem capacidade fiscal, financeira e um plano administrativo competente (BRESSER PEREIRA, 1998).

No advento do gerencialismo na administração pública brasileira, referendou-se, ainda no governo de Fernando Henrique Cardoso (FHC), o pressuposto da governança embasada na teoria da administração de empresas, com o intuito de transformar a então administração burocrática em administração gerencial.

De acordo com Borges (2003, p. 125), esse fato é parte de um movimento internacional, em que a agenda de políticas do Banco Mundial sai das reformas macroeconômicas strictu sensu para focar na reforma estatal e da administração pública, no intuito de estimular a "boa governança" e o fortalecimento da sociedade civil.

Naturaliza-se "a maior participação dos agentes privados e das organizações da sociedade civil, redefinindo os domínios públicos e privados, com foco no atendimento ao cidadão" (OLIVEIRA, 2013, p. 5). A governança incentiva as redes interorganizacionais como meio alternativo para atingir o interesse público (PECI; PIERANTI; RodRIGUes, 2007, p. 3).

Considerando, então, a forte presença do princípio da governança na Nova Gestão Pública (NGP), no âmbito da reforma administrativa, o presente artigo compreende governança pública enquanto ferramenta de gestão, assimilando essa categoria como "a maneira pela qual as instituições são governadas e administradas; é definida como a proteção ao inter-relacionamento entre administração, controle, supervisão e responsabilidade em prestar contas" (SLOMSKI et al., 2008, p.160).

Além dos entendimentos pontuados, há um leque conceituações que interpretam a governança pública. Dentre estas, enfatiza-se o entendimento pontuado pela IFAC e o Tribunal de Contas da União (TCU), em virtude da relevância interferência que os mesmos apresentam no fazer administrativo público brasileiro.

Deste modo, a governança abrange a estrutura (administrativa, política, econômica, social, ambiental, legal, entre outras) que assegura que os resultados almejados pelos interessados sejam definidos e alcançados (IFAC, 2001). De acordo com o TCU (2014), governança no setor público compreende:

\footnotetext{
${ }^{2}$ Vale ressaltar o entendimento de eficiência, que, na perspectiva da IFAC, remete ao "uso de recursos assim que os resultados são maximizados por um grupo determinado de entradas de recursos, ou a entrada é maximizada por alguma quantidade e qualidade determinada de saídas" (SLOMSKI et al., 2008, p.155). Logo, diz respeito à relação mais apropriada entre os resultados e os recursos indispensáveis para sua obtenção (RODRIGUES, 2017, p.90).
} 
Essencialmente os mecanismos de liderança, estratégia e controle postos em prática para avaliar, direcionar e monitorar a atuação da gestão, com vistas à condução de políticas públicas e à prestação de serviços de interesse da sociedade (TCU, 2014, p. 26).

Dessa maneira, este tópico elenca as recomendações acerca da governança das entidades do setor público, a fim de que seja posteriormente utilizado como auxílio aos gestores, no exercício de revisão e desenvolvimento de suas práticas administrativas referentes ao processo de desfazimento.

Nesse sentido, a IFAC 2011, propõe que tal categoria no setor público deve se basear nos pressupostos de transparência, integridade e na responsabilidade de prestar contas. Tais princípios resultaram em algumas recomendações de governança das instituições públicas, elaborado pelo estudo 13 do PSC da IFAC, sejam elas: padrão de comportamento, estruturas e processos organizacionais, controle e relatórios externos.

Acerca dos padrões de comportamento, refere-se à forma como a administração da entidade exerce a liderança em estabelecer quais os valores e padrões da instituição, em delinear a cultura da mesma e o comportamento das pessoas que a compõem. Já a estrutura e processos organizacionais remetem ao modo como a cúpula da administração é formada e organizada, como são determinadas e asseguradas suas responsabilidades.

No tocante ao controle, diz respeito à rede de diversos controles definidos pela cúpula da administração da instituição, utilizados como suporte para a consecução dos objetivos da entidade, da efetividade e eficiência dos procedimentos, da segurança dos relatórios (tanto internos quanto externos), da conformidade aos regulamentos, políticas internas e normativas legais aplicáveis.

Por fim, os relatórios externos denotam a forma que tal cúpula procede à prestação de contas do erário público, como também à satisfação na aplicação de tais recursos. Assim, têm-se esquematicamente as categorias que compõem tais recomendações. 
Quadro 1 - Recomendações de governança no setor público

\begin{tabular}{|c|c|c|}
\hline \multicolumn{3}{|c|}{ Padrões de comportamento } \\
\hline \multicolumn{3}{|c|}{$\begin{array}{l}\text { - Liderança } \\
\text { - Códigos de conduta } \\
\qquad \text { Probidade e propriedade } \\
\bullet \quad \text { Objetividade, integridade e honestidade } \\
\bullet \quad \text { Relacionamento }\end{array}$} \\
\hline $\begin{array}{c}\text { Estruturas e processos } \\
\text { organizacionais }\end{array}$ & Controle & Relatórios externos \\
\hline $\begin{array}{l}\text { Responsabilidade em prestar } \\
\text { conta estatutária } \\
\text { Responsabilidade em prestar } \\
\text { conta pelo dinheiro público } \\
\text { Comunicação com as partes } \\
\text { interessadas } \\
\text { Papéis e responsabilidades: } \\
\text { - Equilíbrio de poder e autoridade } \\
\text { - O grupo do governo } \\
\text { - O presidente } \\
\text { - Membros do grupo do governo não } \\
\text { executivo } \\
\text { - Administração executiva } \\
\text { - Política de remuneração }\end{array}$ & $\begin{array}{ll}\text { - } & \text { Gestão de risco } \\
\text { - } & \text { Auditoria interna } \\
\text { - } & \text { Comitês de } \\
& \text { auditoria } \\
\text { - } & \text { Controle interno } \\
\text { - } & \text { Orçamento } \\
\text { - } & \text { Administração } \\
& \text { financeira } \\
\text { - } & \text { Treinamento de } \\
& \text { pessoal }\end{array}$ & $\begin{array}{ll}\text { - } & \text { Relatórios anuais } \\
\text { - } & \text { Uso de normas } \\
& \text { contábeis } \\
& \text { apropriadas } \\
\text { - } & \text { Medidas de } \\
\text { desempenho } \\
\text { - Auditoria externa }\end{array}$ \\
\hline
\end{tabular}

Fonte: International Federation of Accountants - IFAC (2001, p.14).

A fim de criar uma melhor compreensão, é imprescindível pormenorizar tais recomendações. Nesse sentido, o próximo tópico explana essas categorias, associando-as ao contexto em análise.

\section{Dimensões da governança pública aplicadas ao IFPB}

Passando ao recorte espacial em estudo, para desenvolver a boa governança no contexto do IFPB, foi criado o Planejamento Estratégico Decenal (Planede), que se trata de um planejamento desenvolvido em plataforma eletrônica da instituição.

Assim, "desde 2016, os relatórios oficiais e indicadores de desempenho do IFPB são elaborados dentro do sistema de gestão do Planede 2025" (IFPB, 2018, não paginado). Contudo, esse planejamento não esgota as instâncias a serem examinadas para o bom desempenho da governança, como se percebe na exposição das dimensões a seguir.

No que diz respeito aos padrões de comportamento, considera-se que a imagem da instituição é reflexo do comportamento de todos os que fazem parte da mesma 
(SLOMSKI et al., 2008). Logo, para que os integrantes sejam comprometidos com o padrão de excelência de comportamento pessoal, bem como preservem um relacionamento honesto com os demais integrantes da entidade e com o público, é preciso utilizar procedimentos efetivos e de proteção. No caso do IFPB, campus Campina Grande, podese considerar os servidores efetivos, bem como funcionários contratados.

Dentro desses padrões, encontra-se a categoria de liderança, em que os altos gestores da instituição normalmente definem os padrões e valores que funcionarão para determinar a cultura da instituição e estabelecer o comportamento do corpo de funcionários.

No que concerne ao estabelecimento de tal cultura, é pertinente ressaltar que, de acordo com Laraia (2014), há limitação na participação de um indivíduo na sua cultura, sendo impossível que este conheça e participe de todos os elementos que a compõe:

Embora nenhum indivíduo, repetimos, conheça totalmente o seu sistema cultural, é necessário ter um conhecimento mínimo para operar dentro do mesmo. Além disto, este conhecimento mínimo deve ser partilhado por todos os componentes da sociedade de forma a permitir a convivência dos mesmos (LARAIA, 2014, p. 86).

Logo, mesmo diante do esforço em formar uma cultura institucional robusta, cada servidor irá absorver parte dos seus componentes. Ainda assim, se faz necessário partilhar dos seus elementos essenciais. Neste viés, os diretores geral, administrativo e de educação representam aqui o grupo de liderança máxima do IFPB - campus Campina Grande, cabendo aos mesmos a efetivação de tal influência.

Quanto ao código de conduta, esse deve ser elaborado formalmente e busca estruturar uma cultura institucional que aborde os seguintes temas: integridade, honestidade, objetividade, probidade, propriedade e relacionamento. Nesse sentido, Coutinho (2004) traz em pormenor que:

Para que os funcionários tenham os incentivos corretos, a empresa deve assegurar uma cultura ética e aberta, na qual os membros são encorajados a fazer o certo e sentirem-se habilitados para desafiar decisões gerenciais ou metas que entendam ser antiéticas ou disfuncionais (COUTINHO, 2004, p. 172).

Além do Decreto n ${ }^{\circ}$ 1.171, de 22 de junho de 1994, que traz o Código de Ética Profissional do Servidor Público Civil do Poder Executivo federal, os servidores da instituição em foco dispõem do Código de Conduta Ética dos servidores do Instituto 
Federal de Educação, Ciência e Tecnologia da Paraíba (IFPB, 2018), o qual traz os direitos e obrigações a serem seguidos pelos mesmos.

No que diz respeito ao quesito relacionamento, ainda abarcado pela recomendação do código de conduta, refere-se ao tratamento justo, oportuno, cordial e eficiente ao público. Também se remete à relação entre os membros da instituição, devendo haver respeito, honestidade e cautela entre os servidores.

Aqui, a liderança precisa criar um clima de cultura pública que desenvolva nos membros da instituição confiança na imparcialidade e consistência dos procedimentos, incitando os mesmos a se preocuparem em manter a reputação do local de trabalho.

Acerca das estruturas e processos organizacionais, pode ser entendida como a face operacional do que o código de conduta determina, concentrando, aqui, as seguintes categorias: responsabilidade em prestar conta estatutária, responsabilidade em prestar contas pelo dinheiro público, comunicação com as partes interessadas, papéis e responsabilidades.

A responsabilidade em prestar conta estatutária diz respeito ao estabelecimento da responsabilidade do servidor em agir consoante os estatutos, leis, regulamentações e demais normativas aplicáveis à instituição, bem como "outras demonstrações das melhores práticas" (SLOMSKI et al., 2008, p. 144).

Sobre tais normativas, em nível do IFPB, tem-se a seguinte ordem hierárquica interna: Estatuto; Regimento Geral; Resoluções do Conselho Superior; Resoluções do Conselho de Ensino, Pesquisa e Extensão e do Conselho de Planejamento, Administração e Finanças; Atos Normativos da Reitoria; Atos Normativos das Pró-Reitorias (IFPB, 2015).

Já o campus Campina Grande está em processo de elaboração o Regimento Interno. Em vigor, existem as resoluções do Conselho Diretor do campus e os atos normativos do diretor geral. Há também as normativas externas, concernentes a todos as entidades federais da esfera executiva.

No tocante à responsabilidade pelo dinheiro público, essa consiste em utilizá-lo de forma eficiente. Diz respeito a aspectos financeiros e não-financeiros, incluindo aqui a qualidade dos serviços prestados, bem como a responsabilidade em atender as prioridades da instituição, tendo como fulcro as normativas que controlam o uso desses recursos. 
Um dos indicadores que sugerem a efetividade dessa dimensão, conforme Sales (2014), é se "apresenta disposições adequadas para assegurar o atendimento aos princípios da legalidade e moralidade na utilização dos recursos" (SALES, 2014, p. 107).

$\mathrm{Na}$ categoria comunicação com as partes interessadas, discorre que a administração deve assegurar canais precisos de comunicação com a sociedade, a fim de mantê-la informada sobre seus direitos e serviços ofertados, desenvolvendo e expondo os meios para proceder às investigações, assegurando também aos servidores meios de expor suas reclamações, sem a possibilidade de sofrerem represália por tal iniciativa. De acordo com o relato integrado do IFPB, a instituição busca:

Usar as mídias de comunicação de massa, a exemplo do Portal na web do IFPB e das redes sociais, coordenando de forma estratégica e com base em marketing integrado para garantir a divulgação dos serviços ofertados ao público pelo IFPB, e consequentemente servir como importante elo entre o IFPB, seu corpo dirigente e o cidadão que é ou poderá ser usuário de seus serviços (IFPB, 2018, p. 17).

Ante ao exposto, como fruto da Lei de Acesso à Informação $n^{\circ} 12.527 / 2011$ e do Decreto $N^{\circ} 7.724$, de 26 de maio de 2012, o IFPB disponibiliza o Sistema de Informação ao Cidadão (SIC) que, quando solicitado pelo cidadão, disponibiliza a transparência das informações. Além da ouvidoria, conta com a Carta de Serviço ao Cidadão que, conforme regulamenta o Decreto $\mathrm{n}^{\mathrm{o}}$ 6.932, de 11 de agosto de 2009, apresenta informações da instituição.

Ainda nas estruturas e processos organizacionais, têm-se os papéis e responsabilidades, que discorre sobre as responsabilidades dos servidores e o equilíbrio do poder e autoridade. Incluem as divisões das responsabilidades dos cargos gestores e a assimilação do relacionamento que os mesmos devem possuir com a comunidade.

No equilíbrio do poder e autoridade, constante nos papéis e responsabilidades, a IFAC sugere que seja criada e mantida uma estrutura moderna de restrição e delegação de poderes nos principais cargos da entidade. Uma das maneiras sugeridas pela IFAC, de manter tal equilíbrio, é constar no grupo de tomada de decisões a mesma quantidade de executivos e não executivos.

Considerando que muitas entidades precisam ser dirigidas por um grupo governante satisfatório para guiar e controlar a entidade, monitorando os gestores executivos, a IFAC elenca as responsabilidades, bem como o suporte que deve ser disponibilizado aos principais integrantes da estrutura da instituição, a saber: os membros 
do grupo do governo, o presidente (responsável por buscar assegurar tal suporte aos primeiros), os membros do grupo do governo não executivo e a administração executiva.

O chefe do Executivo, sendo membro do grupo governante ou não, deve ser responsável por todos os aspectos da administração executiva. Correlacionando ao contexto estudado, o reitor desempenha o papel de dirigente máximo do IFPB e o Conselho Superior, o órgão máximo. Inserindo no campus Campina Grande, o dirigente máximo local é o diretor-geral do campus.

Ainda no âmbito de papéis e responsabilidades, recomenda-se a política de remuneração, que enseja incentivar os membros do executivo que logram êxito. Uma vez que a instância de decisão das remunerações é externa ao âmbito institucional, posto que é sancionada pelo Congresso Nacional e executada pelo presidente da República, tornase inviável a análise de tal execução no contexto da instituição. Deste modo, passa-se ao entendimento do controle.

Apesar de existir uma ideia comum entre muitos autores acerca da necessidade do Brasil em avançar no aperfeiçoamento e afirmação do gerencialismo na administração pública, o controle é um conceito de origem burocrática que não se pode eliminar, mas deve ser somado à consciência administrativa dos administrados, a partir do incentivo à construção de um pensamento ético (OLIVEIRA; AlEXANDRINO, 2019, p. 20).

Se por um lado o advento do gerencialismo foi marcado pela mudança de prioridade, que desloca o foco do controle dos processos para os resultados (MATIAS PEREIRA, 2016), por outro, a categoria controle não é extinta, mas reconfigurada. Ainda se faz necessário precaver a administração pública de atos prejudiciais ao seu bom funcionamento (PInHEIRO; Oliva, 2020). Contudo, a utilização dos mecanismos de controle deve estar alinhada às outras dimensões, ou seja, avançar na medida em que se acomoda às demais exigências do gerencialismo, sem coibi-las.

Quanto às exigências trazidas pela IFAC, o controle se relaciona a alguns aspectos, sejam eles: gestão de risco, auditoria interna, comitês de auditoria, controle interno, orçamento, administração financeira, treinamento de pessoal.

Sobre a gestão de risco, Slomski et al. (2008, p. 149) explicam que é assimilada como um processo de compreender os objetivos da instituição e pontuar os riscos relacionados à execução dos mesmos; avaliar, desenvolver melhorias e monitorar os riscos e procedimentos. 
No IFPB, existe a previsão no Planede dessa categoria, onde a análise do risco é feita a partir de subgrupos, sendo descrita como Política de Gestão de Riscos das Atividades de Ensino, Pesquisa, Extensão e Gestão Institucional ${ }^{3}$. Assim, essa gestão de risco é feita a partir dos dados alimentados nesse sistema.

O objetivo dessa previsão consiste em ter cautela nas ações e previsibilidade de contingências na gestão dos subgrupos, denominados de macroprocessos (IFPB, 2018). No contexto do IFPB, a auditoria interna realiza o cálculo da matriz de risco $^{4}$, considerando alguns critérios, incluindo aqui se esse macroprocesso faz parte das ações finalísticas do IFPB.

Abordando a auditoria interna, ela existe para assegurar a revisão sistemática dos programas, a integridade, confiança e conveniência das finanças e demais funções relacionadas a esse aspecto. Contudo, quando os custos não superam os benefícios da implantação de uma auditoria, essa pode ser dispensada. Nesse viés, o IFPB como um todo conta com a auditoria interna, situada na reitoria, tendo o campus sob sua responsabilidade.

Em relação aos comitês de auditoria, sendo compostos por membros externos à administração, devem representar a instituição no relacionamento com a auditoria externa e assegurar o papel e o reconhecimento da auditoria interna. O IFPB não possui comitê de auditoria interna, uma vez que não condiz com a realidade institucional. Portanto, não será utilizada para a análise do desfazimento.

Abordando, então, a subcategoria controle interno, deve ser efetuada pela gestão, como também diretores e demais servidores alocados para esse fim, garantindo confiabilidade das suas operações, efetividade e eficiência dos atos (analisados a partir dos objetivos e metas de desempenho). Deve ser criada uma estrutura em que tal controle opere na prática e apareça sua demonstração no relatório anual da entidade.

Segundo o manual de orientações técnicas de atividade de auditoria interna governamental do Poder Executivo federal (BRASIL/CGU, 2017), um dos pontos a ser considerado no controle interno diz respeito à segregação de funções, em que define como:

Consiste na separação de funções de tal forma que estejam segregadas entre pessoas diferentes, a fim de reduzir o risco de erros ou de ações

\footnotetext{
${ }^{3}$ Disponível em: <http://planejamento.ifpb.edu.br>. Acesso em: 20 dez. 2019.

${ }^{4}$ Entende-se matriz de risco como um instrumento para a gestão que avalia os riscos dos projetos e permite distinguir quais deles envolvem maiores e menores riscos.
} 
inadequadas ou fraudulentas. Geralmente implica dividir as responsabilidades de registro, autorização e aprovação de transações, bem como de manuseio dos ativos relacionados (BRASIL/CGU, 2017, p. 136).

Quanto ao controle interno a ser efetivado pela gestão, o IFPB, por meio do Planede, propõe como instrumentos de controle uma série de elementos, a exemplo do Mapa Estratégico, Indicadores de Desempenho e legislações referentes à educação (IFPB, 2018, p. 40).

Somados a esses, realizam-se reuniões sistêmicas para acompanhar as demandas e solucionar problemas nas distintas instâncias da gestão, realçando as instâncias colegiadas no acompanhamento do cumprimento dos valores e missões da instituição, bem como dos planos ligados a sua consecução (como o PNE, PDI, PPC's, Planede), a fim de conferir a adequação e eficácia dos atos e verificar onde as melhorias devem ser focadas (IFPB, 2018, p. 83).

Embarcando na análise do próximo tópico, o IFPB como um todo possui auditoria interna enquanto órgão auxiliar do Conselho Superior, ou seja, possui independência quanto à gestão administrativa, conforme sugere a IFAC e abrange todos os campi. Desse modo, observa-se:

A Auditoria Interna é o órgão de controle interno da administração do IFPB, com a finalidade de avaliar a conformidade dos atos administrativos com a legislação e as normas internas pertinentes, além de auxiliar os órgãos de controle externo (IFPB, 2017, art. 38).

Além destas atribuições, a auditoria faz a análise da prestação de contas anual e emite parecer, subsidiando a administração superior da instituição a fim de corrigir desconformidades e analisar casos determinados pelo Conselho Superior, com posterior emissão de relatório de auditoria sobre esses (IFPB, 2018, p.18).

Passando a abordar o orçamento, ele configura-se como um mecanismo de alocar recursos com vista a atingir objetivos, é um instrumento de gestão essencial para o planejamento financeiro, devendo ser integrado com a contabilidade. No Brasil, o Legislativo que aprova o orçamento. Nos limites desse nível geral, o Executivo efetua o plano financeiro.

Quanto à administração financeira, tem a função de dar assistência no âmbito administrativo diante dos recursos limitados. A Direção-Geral, assessorada pela Direção 
de Administração, Planejamento e Finanças do IFPB - Campus Campina Grande, que deve, prioritariamente, desempenhar tal função em nível local.

Nesse escopo, o processo de alienação só deve ocorrer diante da não serventia do bem, e não prioritariamente enquanto objeto de receita, especialmente em uma instituição de educação que não tem por objetivo auferir lucro. Acerca desse entendimento, a normativa interna pontua:

Art. 262. Os bens imóveis, equipamentos e instalações do IFPB são utilizados pelos diversos órgãos que compõem a Reitoria e os campi, exclusivamente, para a consecução de seus objetivos, não podendo ser alienados, a não ser nos casos e condições permitidos por lei (IFPB, 2017, art. 262).

Por tais motivos, frisa-se que administração financeira e orçamento não se enquadram na análise do desfazimento na instituição estudada, posto que a natureza dos mesmos é de cunho financeiro, divergindo do objetivo do processo de desfazimento.

Embarcando no treinamento pessoal enquanto instrumento de controle, as recomendações voltam-se para que seja investido em programas de treinamento e políticas de recrutamento que auxiliem para a construção de uma força de trabalho competente. Logo, faz-se necessário que exista capacitação adequada dos servidores para que realizem satisfatoriamente o processo de desfazimento.

No IFPB, o Conselho Superior, enquanto órgão máximo da instituição delibera acerca da política de capacitação a ser definida anualmente para seus servidores. Dessa forma, de acordo com o PDI 2015 a 2019, busca-se o fomento e incentivo ao aperfeiçoamento constante do seu corpo de funcionários.

Esclarecido esse ponto, parte-se, então, para a indicação da IFAC voltada aos relatórios externos, associando-os aos relatórios anuais, a utilização de normas contábeis adequadas, as medidas de desempenho, bem como a auditoria externa.

No que tange ao relatório anual, a instituição deve publicá-lo a cada final do ano financeiro, demonstrando sua responsabilidade na prestação de contas do serviço público. Aqui, deve trazer demonstrações financeiras que foram auditadas, bem como relatórios dos auditores, os desempenhos (financeiros e não financeiros) do órgão. Além disso, incluir demonstração que explique sua responsabilidade em apoiar e assegurar o uso das normas contábeis.

A auditoria do IFPB produz o Relatório Anual de Atividades de Auditoria Interna (RAINT), que traz as ações efetivadas desse órgão, sendo submetido ao Conselho 
Superior, bem como à Controladoria Geral da União (CGU). Além desse relatório, existe o Relatório de Gestão integrado com a Prestação de Contas Ordinária ${ }^{5}$.

Acerca do Relatório anual da gestão, o IFPB disponibiliza o Relatório de Gestão, que consiste na prestação de contas ordinária anual, publicado no Portal TCU e também no Portal da Transparência do IFPB, para fins de consulta pública (IFPB, 2019). Nesse contexto, este passa pela apreciação do Conselho Diretor, que emite parecer conclusivo quanto à regularidade e propriedade dos registros. Contudo, trata-se de um relatório condensado, apresentando as informações do IFPB como um todo, sem especificar por campus.

Quanto ao uso de normas contábeis apropriadas, nas palavras de Slomski et al. (2008, p. 154) é necessário que o governo assegure que as demonstrações financeiras presentes no relatório anual estejam de acordo com as normas internacionais de contabilidade pública ou demais "grupos autorizativos e reconhecidos de normas contábeis, e a legislação aplicável".

Com a edição da Portaria MF $\mathrm{n}^{\circ}$ 184, de 25 de agosto de 2008, que rege as diretrizes a serem consideradas no setor público, no tocante aos procedimentos utilizados na formulação e publicação das demonstrações contábeis, buscou-se convergir a contabilidade pública aos padrões da IFAC. A partir desse momento, o MCASP e o Manual do Sistema Integrado de Administração Financeira do Governo Federal (Siafi ${ }^{6}$ ) passaram a adotar esse padrão contábil na esfera do Governo Federal.

Em suma, a Secretaria do Tesouro Nacional (STN), enquanto órgão central de contabilidade deve ter seus manuais, normativas e instruções procedimentais em consonância com as Normas Brasileiras Aplicadas ao Setor Público (NBCT SP), que são editadas pelo Conselho Federal de Contabilidade (CFC), e também com as Normas Internacionais de Contabilidade Aplicadas ao Setor Público (IPSAS), editadas pela IFAC. Para melhor visualização, segue figura esquemática com a estrutura da elaboração da contabilidade pública:

\footnotetext{
${ }^{5}$ Existe a exigência legal destes relatórios como prestação de contas. Versam sobre essa questão, o art. 70 da Constituição Federal, a Instrução Normativa TCU n ${ }^{\circ}$ 63/2010, a Decisão Normativa TCU nº 170/2018 (Relatório de Gestão), e a Portaria TCU nº 369/2018.

6 "O Siafi é um sistema informatizado que processa e controla, por meio de terminais instalados em todo o território nacional, a execução orçamentária, financeira, patrimonial e contábil dos órgãos da administração pública direta federal, das autarquias, fundações e empresas públicas federais e das sociedades de economia mista que estiverem contempladas no Orçamento Fiscal e/ou no Orçamento da Seguridade Social da União" (BRASIL, 2020, não paginado).
} 
Figura 1 - Modelo de implementação das normas contábeis públicas do Brasil

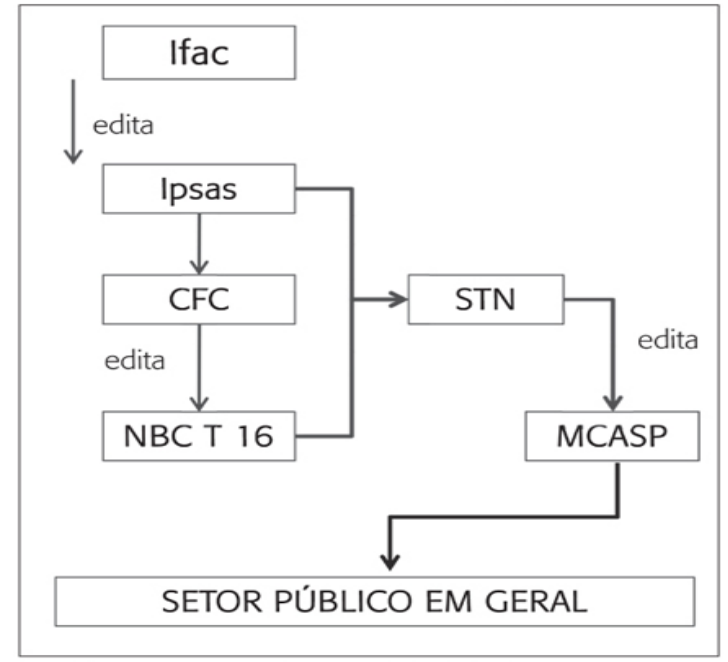

Fonte: Gama, Duque e Almeida (2014, p. 197).

Observando a hierarquia dessas normas e, consequentemente, a posição de destaque do IFAC diante dos demais, entende-se a importância de considerar as recomendações desse órgão na atuação pública.

A Secretaria do Tesouro Nacional disponibiliza Manual de Normas e Procedimentos Operacionais de Regularização de Obrigações, no qual está inserido o Manual do Siafi. Esse, por sua vez, dispõe de explicações mais detalhadas dos procedimentos operacionais contábeis, a fim de padronizar os critérios das entidades públicas, gerando dados comparáveis e mais consistentes (BRASIL, 1996).

Assim como as demais instituições do Executivo federal, o IFPB segue a hierarquia acima citada. Existe um documento formulado no âmbito institucional que serve como aporte na aplicabilidade dessas normas, denominado "Manual de Procedimentos Contábeis do IFPB” (IFPB, 2017). Este também enfatiza a importância de qualificar e padronizar os atos e fatos da administração no contexto dessa entidade (IFPB, 2017, p. 3).

Quanto às ferramentas para executar as normas contábeis apropriadas, Barcellos e outros (2017) ponderam que:

Cabe ressaltar que os novos padrões para a contabilidade pública direcionam o foco da contabilidade à correta mensuração e evidenciação do patrimônio público, adicionando novas práticas de mensuração a valor justo (valor de mercado) e da redução pelo ajuste de recuperabilidade no futuro (impairment). A manutenção do sistema deve ser observada constantemente, não somente pela manutenção cadastral dos bens patrimoniais, mas também pela sua adequação às normas contábeis e alterações na legislação fiscal pertinente. (BARCELLOS et al., 2017, p. 81) 
Neste campo, adaptando esse entendimento ao contexto do IFPB, observa-se que, para a aplicabilidade dessas normas, faz-se necessário que a mesma tenha como aporte um sistema robusto, ou seja, que os sistemas Siafi e Sistema Unificado de Administração Pública (Suap) ${ }^{7}$, contemplem as exigências contábeis que a instituição deve seguir.

Compreendida a estruturação das normas, serão abordadas as medidas de desempenho. As informações sobre o desempenho, segundo a IFAC, podem ser solicitadas pela gestão para avaliar onde e quando aplicar os recursos, e ainda auxiliam os usuários internos na melhoria dos processos. Tais informações são importantes também para os cidadãos avaliarem se a instituição está alcançando seus objetivos e se os gastos são necessários.

Nesse sentido, essas medidas de desempenho devem fazer comparação com instituições similares e com as metas estabelecidas, devendo verificar as seguintes categorias: economia, eficiência ${ }^{8}$, efetividade e conveniência (SLOMSKI et al., 2008, p. $155)$.

A esse respeito, Amorim, Diniz e Lima (2017) explicam que:

De acordo com Pacheco (2009) existem diversos problemas nos indicadores de mensuração de desempenho; contudo, a contribuição que eles oferecem à avaliação da gestão, tanto na mensuração de resultados quanto na transparência das informações, auxilia na identificação da efetividade dos resultados produzidos (AMORIM; DINIZ; LIMA, 2017, p. 58).

O Acórdão TCU n 2.267/2005 determina a inclusão de alguns indicadores de desempenho a serem integrados ao relatório de gestão das contas anuais dos Institutos Federais de Educação Tecnológica (IFETs). Tais índices remetem em sua maioria a aspectos relacionados ao corpo discente, além dos gastos com pessoal, investimentos e outros custeios.

Nesse sentido, o IFPB utiliza como fonte para o preenchimento dessas dimensões os dados cadastrados na Plataforma Nilo Peçanha (PNP), que consiste em um ambiente virtual que coleta, valida e dissemina as estatísticas oficiais da Rede Federal de Educação Profissional, Científica e Tecnológica (Rede Federal), referentes ao corpo discente,

\footnotetext{
${ }^{7}$ Sistema para gestão de processos administrativos operado no IFPB que dispõe do módulo patrimônio utilizado pelo setor na gestão dos bens permanentes.

8 Para Martínez e Rueda (2005), a avaliação da eficiência na educação pública apresenta diversas dificuldades metodológicas e possuem influência de fatores externos. Page (2004) recomenda que a coleta de dados seja bem simples e avalie as prioridades da instituição.
} 
docente, técnico-administrativo e aos gastos financeiros das unidades da Rede Federal (PNP, 2018).

Por fim, na auditoria externa, é preciso um Comitê de Auditoria enquanto subcomitê da gestão que conduza o relacionamento com os auditores externos. É importante dar destaque ao fato de que, segundo estudo intitulado de "A governança no setor público segundo a IFAC: uma análise dos Institutos Federais da Região Sul do Brasil", a subcategoria Auditoria externa, citada em "Relatórios Externos", foi excluída da sua análise.

O referido trabalho considerou que o subtópico em debate não corresponde à realidade dos Institutos estudados e/ou não foi possível detectar a conformidade por meio da análise dos documentos (PAines; AguiAr; PinTo, 2018, p. 236). Dessa maneira, o presente estudo compartilha da visão acima, quanto à impossibilidade de aplicar esse subtópico na análise dos dados referentes ao IFPB - campus Campina Grande.

\section{Análise do desfazimento de bens do IFPB - campus Campina Grande}

Passa-se então à abordagem específica do nível de aderência das práticas de alienação de bens móveis permanentes às recomendações de boa governança proposta pela IFAC. Uma vez que no IFPB- campus Campina Grande foi constatada apenas uma alienação, seja ela a doação de bens, ocorrida no ano de 2017, a análise tem como enfoque tal processo.

O desfazimento no campus Campina Grande iniciou com a constituição da Comissão de desfazimento, por meio de uma portaria emitida pela Direção-Geral (DG). Contudo, encerrado o prazo desse documento, o processo não foi efetivado, sendo restituída a portaria a fim de que a Comissão apresentasse o trabalho concluído.

A esse respeito, é importante ressaltar o que aborda o Código de Conduta do Servidor do IFPB:

Hábil, com eficiência e eficácia, dentro do horário e calendário institucionalmente previsto, pondo fim ou procurando prioritariamente resolver situações procrastinatórias, principalmente diante de filas ou de qualquer outra espécie de atraso na prestação dos serviços pelo setor em que exerça suas atribuições, com o fim de evitar dano moral ao usuário (IFPB, 2018).

Uma vez que o procedimento não correspondeu ao tempo estipulado em portaria, sugeriu-se, a princípio, que os servidores não atenderam ao quesito eficiência no serviço 
em execução. Contudo, foi observado que as incertezas em como conduzir o processo (os trâmites a cumprir) pela comissão e identificar os materiais (houve dificuldade em associar os objetos ao seu tombo, posto que maior parte estava deteriorada) resultaram no aumento do tempo necessário para a consecução.

Outra questão, diz respeito ao encaminhamento do patrimônio. Após a ratificação pela DG das sugestões elencadas pela comissão, a relação dos bens de informática foi enviada à Secretaria de Normas e Sistemas de Logística (Seges) do Ministério do Planejamento, Desenvolvimento e Gestão, seguindo a exigência do Decreto $\mathrm{n}^{\mathrm{o}}$ 99.658/1990, que regulamentava o processo de desfazimento à época.

No entanto, em face da vigência do Decreto $\mathrm{n}^{\circ}$ 7175, de 12 de maio de 2010, a referida secretaria encaminhou a relação ao MCTIC (Ministério da Ciência, Tecnologias e Inovações). Esse redirecionamento resultou em atraso na execução do processo, uma vez que entre o envio da relação pelo IFPB e o recebimento da autorização para seguir o desfazimento, conforme constatado no relatório do processo, deu-se no intervalo de aproximadamente quarenta dias, comprometendo a eficiência da execução.

Apesar de inicialmente a equipe não possuir entendimento suficiente para realizar o processo (fortalecido pela legislação que não traz os esclarecimentos necessários) observa-se que, no desenvolver do mesmo, o desfazimento teve a colaboração da função liderança, representada pela DG.

Com a emissão da segunda portaria que designou a Comissão de Desfazimento, o diretor-geral se reuniu com a mesma e explicou a importância de disponibilizar o edital no site institucional e a publicação de extrato no Diário Oficial da União (DOU), além do edital. Assim, buscou-se seguir todas as etapas necessárias para dar visibilidade, transparência e impessoalidade ao processo.

Após tal explanação, verifica-se a aplicabilidade da categoria padrão de comportamento, que abarca as subcategorias liderança e código de conduta (abrangendo, esse último, os aspectos de probidade e propriedade; objetividade, integridade e honestidade e relacionamento).

Conforme elucidado, acerca da liderança, apesar de não ser eminente a figura da DG durante o período que vigorava a primeira portaria da Comissão de Desfazimento, essa se fez presente quando a mesma foi restabelecida, determinando os padrões a serem seguidos. 
Quanto ao código de conduta, não foram debatidos com a equipe de desfazimento os códigos de ética aos quais os servidores estavam subordinados, mas houve diálogo que contemplou alguns dos seus elementos, a saber: a integridade, a honestidade, a probidade e o relacionamento.

Nesse contexto, observa-se que a escolha pelo desfazimento, buscou-se promover os atos considerados mais justos pela sociedade, o intercâmbio de ideias e opiniões (por ser discutida entre os servidores da Comissão), propiciando o respeito ao patrimônio público, pontos esses trazidos pelo Código de Conduta Ética dos servidores do IFPB.

A sequência dos trâmites do processo, os métodos de tomada de decisão (constando, no processo, ata da reunião com o deferimento pela autoridade competente), o cumprimento de etapas que seguissem a legalidade do processo, a inclusão de imagens dos bens anexo ao processo, a fim de torná-lo o mais completo possível, revelam o cuidado em respeitar a integridade, a probidade e a honestidade no processo em questão.

Contudo, diante das circunstâncias explanadas, verificou-se que a eficiência do processo, requerida pelo código de conduta federal e institucional, ficou comprometida. Apesar de existir uma cultura ética e aberta, os membros não se sentiam habilitados para os desafios do processo, conforme sugerido por Coutinho (2004, p .172).

Ainda acerca do código de conduta, importa destacar que a subcategoria relacionamento, que realça a importância de os servidores confiarem na justiça e imparcialidade dos procedimentos adotados, e também assumirem a preocupação em manter a reputação do instituto (SLOMSKI et al., 2008, p 143-144), foi alcançada após a reunião em comento.

Na sequência, analisando o desfazimento dentro do aspecto estrutura e processos organizacionais, percebe-se que atendeu a responsabilidade estatutária, em agir consoante as normas institucionais, seguindo os passos elencados pelo Manual do Patrimônio que, apesar de não trazer todas as instruções necessárias, explica o processo em linhas gerais.

Outro documento de alta relevância a ser observado é o Plano de Desenvolvimento Institucional. Ele traz como valor o "compromisso social e ambiental - participa efetivamente das ações sociais e ambientais, cumprindo seu papel social de agente transformador da sociedade e promotor da sustentabilidade" (IFPB, 2015, p. 12). Nesse viés, entende-se que perseguir esses valores na escolha da melhor forma de desfazimento também é cumprir a dimensão da responsabilidade estatutária. 
A instituição vencedora do certame de doação foi a Oscip denominada de "O Resgate", a mesma é voltada para a recuperação de dependentes alcoólicos e químicos, executando ações e projetos que buscam:

\begin{abstract}
I-promoção da assistência social às minorias e excluídos, desenvolvimento econômico e combate à pobreza; II- promoção gratuita da educação e da saúde incluindo prevenção de HIV-AIDS e consumo de drogas; III- preservação, defesa e conservação do meio ambiente e promoção do desenvolvimento sustentável; IV- promoção do voluntariado, de criação de estágios e colocação de treinandos no mercado de trabalho" (Estatuto Social da Instituição Social - O Resgate - arquivo IFPB, não publicado).
\end{abstract}

Nessa perspectiva, o desfazimento propiciou a efetivação dos valores institucionais, permitindo que o patrimônio atendesse ao compromisso social e ambiental pontuado pelo PDI, destinando seus bens à instituição que desenvolve atividades embasadas em objetivos comuns ao IFPB. Feitas essas considerações acerca da responsabilidade estatutária, segue a análise dos fatos que se relacionam a responsabilidade pelo erário público.

A destinação dos materiais deu-se pelo entendimento de que, por mais que a maior parte dos bens se apresentasse absolutamente deteriorados, dependendo das atividades realizadas, a instituição ganhadora poderia reaproveitá-la como material para produção de novos bens. Nesse momento, a comissão lançou a doação em lote único, somando os bens totalmente deteriorados aos objetos em condições físicas mais favoráveis na tentativa de que a instituição conferisse utilidade a tais materiais.

Em virtude dessa situação, a Coordenação do Patrimônio e Almoxarifado (CAP) disponibilizou fotos dos itens no site e sugeriu visitas das entidades interessadas, a fim de que as mesmas conhecessem a real condição dos bens. Nesse sentido, é relevante destacar que a legislação em vigor permitia o abandono ou inutilização dos bens irrecuperáveis.

Logo, diante da inservibilidade, coube à administração, a partir dos critérios legais e morais (parâmetros sugeridos por Sales (2014) como indicadores de responsabilidade com o referido erário), fazer uma análise da melhor forma de aproveitamento dos bens. Desse modo, optar prioritariamente pelo processo de doação a todos os bens, em detrimento do abandono ou inutilização, seguindo um leque de trâmites, primou pela responsabilidade com o dinheiro público.

É pertinente ressaltar que a entidade vencedora também traz como uma das suas atividades o trabalho com reaproveitamento e reconstrução dos objetos pelos seus 
assistidos, possibilitando, assim, que os itens sucateados servissem como material para o desenvolvimento de suas práticas. Logo, maximizar a utilização dos bens respondeu positivamente a tal recomendação.

Em relação à comunicação com as partes interessadas, também inserida em estruturas e processos organizacionais, o IFPB tem disponível a ouvidoria. Desse modo, esse canal encontrava-se à disposição durante o processo de desfazimento, apesar de não ser citado em publicações referentes ao mesmo.

O campus Campina Grande conta ainda com a Assessoria de Comunicação (Ascom), que faz o intermédio com a sociedade por meio de contato com os meios de comunicação extraoficiais e publicações oficiais. Esse setor que realizou a publicação de edital no site institucional e em meio de comunicação de grande circulação, assegurando a transparência e comunicação com a sociedade, disponibilizando também o contato telefônico da CAP, que foi utilizado pela comunidade para sanar as dúvidas referentes ao processo.

Abordando o tópico papéis e responsabilidades, a IFAC reporta-se à recomendação de manter o equilíbrio de poder e autoridade, com uma estrutura moderna de restrição e delegação de poderes.

Neste sentido, o manual do patrimônio do IFPB discorre, em linhas gerais, que cabe à comissão todo o processo de desfazimento, ficando a cabo da autoridade competente acatar ou não a indicação do tipo escolhido por esses servidores. Também delega ao setor de patrimônio dar baixa no sistema, bem como repassar à contabilidade, para registro contábil.

Dessa maneira, verifica-se que o desfazimento obteve esse equilíbrio, tendo em vista que o processo em si teve seu papel distribuído entre a comissão, o setor de contabilidade, o setor de patrimônio e a Direção-Geral do campus. Contudo, como dois servidores da comissão pertencem à CAP, conforme cruzamento de dados do relatório final do desfazimento e da portaria de nomeação, esse é um ponto que necessitaria de ajuste, como análise posterior em tópico específico.

Adentrando na análise da dimensão controle, passa-se à compreensão de como se deu a gestão de risco. Trazendo esse conceito para o processo de desfazimento, configurase na análise dos riscos existentes na execução desse processo, a fim de minimizar ou dirimir os possíveis impactos negativos. 
Apesar de o Planede trazer a proposta de realizar a gestão de risco, não foi verificada nenhuma informação pertinente à análise de desfazimento no campus Campina Grande. Em nível do IFPB - campus Campina Grande, a avaliação dos riscos foi focada em como realizar os trâmites burocráticos do processo, no sentido de obedecer à sua legalidade para não comprometer a lisura do processo. A falta de experiência anterior, por ser o primeiro processo de desfazimento do campus a ser concluído, trouxe limitações quanto à identificação de riscos e desenvolvimento de melhorias.

Outra análise ocorreu acerca dos itens absolutamente deteriorados. Havia o risco de as instituições desistirem do recebimento em virtude desses objetos se encontrarem bastante danificados, e, por conseguinte, continuarem ocupando espaços da instituição e comprometendo a insalubridade dos espaços.

Em caso de não haver interessados em receber os materiais, havia a possibilidade de o IFPB fazer outro processo, constando apenas os itens menos deteriorados, e procedendo com o abandono dos demais. Logo, verifica-se que a gestão de risco não foi rigorosamente efetivada. Cumprida a análise dessa subcategoria, o estudo segue com a verificação do quesito auditoria interna.

Como visto anteriormente, o IFPB possui auditoria interna, e essa realiza o controle interno da instituição. A auditoria elabora o Plano Anual de Atividades de Auditoria Interna (Paint), o qual prevê as ações ou macroprocessos que serão feitos no ano. A partir dele, é elaborado o programa de auditoria, que seria o planejamento mais operacional que traz efetivamente o setor e, por vezes, os processos que serão avaliados.

Contudo, após análise em relatórios de auditoria e observação das rotinas do setor patrimonial, constatou-se que o IFPB - campus Campina Grande nunca foi alvo de auditoria interna. Dessa maneira, no último Relatório Anual - 2018 (IFPB, 2018), os macroprocessamentos "Gerir Patrimônio" e "Gerir Sustentabilidade Ambiental e Responsabilidade Social", aos quais pode-se associar o processo de desfazimento, obtiveram riscos menores. Logo, a probabilidade de o processo passar por auditoria era mínima.

Em relação ao controle interno a ser executado pela gestão e demais servidores, existe a proposta do Planede, a partir da alimentação da plataforma por cada campus/setor, em perseguir tal controle. Contudo, verificou-se que a alimentação dessa plataforma não tem feito parte das rotinas dos gestores do campus em análise. 
Quanto às reuniões sugeridas pelo Planede, até a realização do desfazimento no campus, não houve reunião sistêmica das coordenações de Patrimônio do IFPB para que se estabelecesse acompanhamento das demandas do setor e soluções dos seus problemas, incluindo o processo de desfazimento.

Ainda na abrangência do controle, discute-se o subtópico treinamento de pessoal. Nesse viés, uma vez que os procedimentos de recrutamento e contínuo treinamento é uma das ações recomendadas pela IFAC, é relevante destacar a composição da equipe da Comissão de Desfazimento.

Dois terços da equipe haviam participado de treinamento de gestão patrimonial, enquanto servidores lotados na CAP, no ano de 2015, que trazia o desfazimento de bens como um dos tópicos abordados ${ }^{9}$. O curso explanou diversos temas de gestão patrimonial, dispensando tempo insuficiente para algo com expressiva complexidade como o desfazimento. Assim, tal capacitação serviu como auxílio, mas o treinamento não esgotou todas as dificuldades que, por sua vez, eram ainda desconhecidas à época do curso.

Apesar de um integrante não ter participado de capacitação, sua contribuição foi imprescindível, em virtude de sua especialidade técnica em computação, para avaliar os materiais de informática, que dispensa avaliação mais detalhada dos seus componentes. Outro participante da comissão, além da experiência e capacitação na gestão patrimonial e formação em Direito, possui na graduação em Tecnologia em Telemática, conhecimento esse que auxilia na análise do material citado.

A experiência em gestão patrimonial da maior parte da equipe facilitou o trabalho sendo assim favorável ao quesito de treinamento de pessoal, uma vez que a Comissão de Desfazimento contava com dois terços da equipe pertencentes à CAP. Contudo, esbarrou no princípio de segregação de funções, que é um dos aspectos do controle interno a ser observado.

Assim posto, uma vez que os bens são direcionados ao desfazimento pela CAP, setor que dois integrantes da Comissão de Desfazimento faziam parte, seguindo a orientação da CGU, o ideal seria evitar que as fases dos processos iniciassem e concluíssem a partir dos mesmos servidores.

Partindo para os relatórios externos das recomendações, especificamente o tópico denominado relatório anual, o IFPB disponibiliza o Relatório de Gestão, que

\footnotetext{
${ }^{9}$ Ver programação completa em http://www.mtfunai.com.br/mar162.jpg
} 
consiste na prestação de contas ordinária anual, publicado no Portal TCU e também no Portal da Transparência do IFPB, para fins de consulta pública (IFPB, 2018).

Quanto ao relatório anual de gestão, referente ao ano de 2017, ano em que foi realizada a doação de bens no campus em estudo, há uma seção que apresenta os trabalhos realizados, bem como os resultados obtidos.

Apesar de pontuar processos iniciados ou desenvolvidos do desfazimento de alguns campi, uma vez que o relatório traz informações minuciosas do desfazimento dos demais campi, como constituição de comissão de desfazimento, reunião, elaboração do processo, o mesmo não expõe o desfazimento de bens realizados pelo campus Campina Grande. Desse modo, o tópico relatório anual não foi atendido satisfatoriamente.

Analisando o subtópico convergência das normas contábeis, verificou-se que, antes da realização do processo, já existia a inconsistência do valor contábil líquido do bem, posto que o sistema Suap não disponibilizava a depreciação e também não possibilitava a reavaliação.

Dessa maneira, a reavaliação do valor contábil dos bens, com base no valor de mercado, não foi efetivada e o cadastro dos bens no Suap não representava o valor dentro dos ditames contábeis. Conforme pontuado, acerca da manutenção do sistema para adequar-se às normas contábeis (BARCELLOS, 2017, p. 81), o processo não atendeu à convergência às normas contábeis.

No entanto, como o sistema Siafi também não realiza a depreciação, a baixa no sistema contábil apresentou conformidade de valor na baixa patrimonial do Sistema Unificado de Administração Pública (Suap), sistema esse onde é efetuado o controle dos bens.

Logo, se por um lado não atendeu à exigência contábil que aborda a reavaliação, por outro, entende-se que a não incorporação dos valores reavaliados dos bens irrecuperáveis (que, por sua vez, eram irrisórios) evitaria trabalho custoso e meramente formal, atendendo à normativa que pontua que "o trabalho administrativo será racionalizado mediante simplificação de processos e supressão de controles que se evidenciarem como puramente formais ou cujo custo seja evidentemente superior ao risco" (BRASIL, 1967, art. 14).

No que se refere a indicadores de desempenho, não existe dimensão específica para o desfazimento na instituição. O processo foi executado a partir de alguns princípios da administração pública, a saber: a legalidade, impessoalidade, moralidade, além do 
interesse público. Contudo, após a realização do processo, não foi realizada a análise do alcance de tais pontos.

\section{Considerações finais}

Diante dos resultados evidenciados, quanto à aderência das recomendações de boa governança ao desfazimento de bens no campus Campina Grande do IFPB, observou-se que a dimensão padrões de comportamento, refletida no quesito liderança e código de conduta, foi alcançada, exceto no que concerne à eficiência do processo.

Acerca das estruturas e processos organizacionais, respondeu satisfatoriamente a todos os seus subelementos, que por sua vez abarcam a responsabilidade em prestar conta estatutária, responsabilidade pelo dinheiro público, comunicação com as partes interessadas e os papéis e responsabilidades.

No tocante à categoria controle, não houve execução plena em nenhuma das subdimensões analisadas, seja na gestão de risco, auditoria interna, controle interno ou treinamento de pessoal (sendo essa última atendida em parte). Da mesma forma, em relação aos relatórios externos, também não houve êxito nas subdimensões examinadas, a saber: os relatórios anuais, o uso das normas contábeis apropriadas e as medidas de desempenho.

Destarte, considera-se parcialmente satisfatória a aplicação das recomendações para a boa governança pública elencadas nas recomendações, necessitando ampliar sua aderência nas categorias controle e relatórios externos.

Em que pese as análises realizadas, este artigo não esgota as possibilidades de melhorias na alienação de bens demandadas pela nova conjuntura visualizada na estrutura administrativa do país, que requer a utilização mais efetiva da governança enquanto instrumento de gestão. Contudo, anseia-se que ele traga contributos para que o processo de desfazimento se realize em maior consonância com tais requisições.

\section{Referências}

AMORIM, Klerton Andrade Freitas de; DINIZ, Josedilton Alves; LIMA, Severino Cesário de. A visão do controle externo da eficiência dos gastos públicos com educação fundamental. Revista de Contabilidade e Organizações, v. 11, p. 56-66, 2017.
BARCELlos, Bruno Maldonado et al. Gestão patrimonial e logística no setor público. Porto Alegre: SAGAH, 2017.

BRASIL. Ministério da Transparência e Controladoria-Geral da União. Manual de orientações técnicas da atividade de auditoria interna governamental do Poder Executivo 
Federal. 2017. Disponível em: http://conaci.org.br/wpcontent/uploads/2018/06/Apresenta\%C3\%A7\% C3\%A3o-MOT.pdf. Acesso em: 05 jan. 2020.

BRASIL. Decreto-Lei no ${ }^{\circ} 200$, de 25 de fevereiro de 1967. Dispõe sobre a organização da Administração Federal, estabelece diretrizes para a Reforma Administrativa e dá outras providências Disponível em: http://www.planalto.gov.br/ccivil 03/decretolei/del0200.htm. Acesso em: 05 jan. 2020.

BRASIL. Lei $\mathrm{n}^{\circ} 11.892$, de 29 de dezembro de 2008. Institui a Rede Federal de Educação Profissional, Científica e Tecnológica, cria os Institutos Federais de Educação, Ciência e Tecnologia, e dá outras providências. Disponível em:

http://www.planalto.gov.br/ccivil_03/_Ato2007 -2010/2008/Lei/L11892.htm. Acesso em: 05 jan. 2020 .

BRASIL. Lei no 4.320, de 17 de março de 1964.

Estatui Normas Gerais de Direito Financeiro para elaboração e controle dos orçamentos e balanços da União, dos Estados, dos Municípios e do Distrito Federal Disponível em:

http://www.planalto.gov.br/ccivil_03/leis/14320. htm. Acesso em: 05 jan. 2020.

BRASIL, Tesouro Nacional. Manual SIAFI. 1996. Disponível em https://conteudo.tesouro.gov.br/manuais/module s/mod_pdf_manual/pdf/manual-siafi.pdf Acesso em: 05 fev. 2020.

BRASIL, Tesouro Nacional. O que é o SIAFI? Brasília, 2020. Disponível em: https://www.gov.br/tesouronacional/ptbr/siafi/conheca/o-que-e-o-siafi. Acesso em: 31 out. 2020 .

BRASIL, Tribunal de Contas da União. Governança pública: referencial básico de governança aplicável a órgãos e entidades da administração pública e ações indutoras de melhoria. Brasília: TCU. Secretaria de Planejamento, Governança e Gestão, 2014.

BORGES, André. Governança e política educacional: a agenda recente do Banco Mundial. Revista Brasileira de Ciências Sociais, v. 18 , n. 52, p. 125-138, 2003

Bresser PeReIRA, Luiz Carlos. Reforma do Estado para a cidadania: a reforma gerencial brasileira na perspectiva internacional. São Paulo: Ed. 34; Brasília: Enap, 1998.

Coutinho, Roberto de Andrade. Gestão patrimonial na administração pública. Rio de Janeiro: Lúmen Júris, 2004.

Gama, J. R.; DuQue, C. G.; Almeida, J. E. F. Convergência brasileira aos padrões internacionais de contabilidade pública vis-à-vis as estratégias top-down e bottom-up. Revista Administração Pública, v. 48, n. 1, p. 183-206, fev. 2014.

INTERNATIONAL FEDERATION OF ACCOUNTANTS - IFAC. Governance in the public sector: a governing body perspective. New York: [s.e.], 2001 .

IFPB. Planede é vetor de desenvolvimento no IFPB. $2018 . \quad$ Disponível em: https://www.ifpb.edu.br/noticias/2018/12/plane de-e-vetor-de-desenvolvimento-no-ifpb. Acesso em: 12 dez. 2019.

IFPB. Relato integrado. 2018. Disponível em: https://www.ifpb.edu.br/transparencia/relatorios -anuais-de-gestao/ifpb-relatorio-de-gestao2018.pdf . Acesso em: 05 jan. 2020

IFPB. Regimento Geral do IFPB. 2017. Disponível em: https://www.ifpb.edu.br/transparencia/document os-institucionais/documentos/resolucao-no144.pdf/view. Acesso em: 05 jan. 2020.

IFPB. Relatório anual de gestão. 2017. Disponível em: https://www.ifpb.edu.br/transparencia/relatorios -anuais-de-gestao. Acesso em: 05 jan. 2020.

IFPB. Manual de procedimentos contábeis. 2017. Disponível em:

https://www.ifpb.edu.br/praf/assuntos/document os-praf/gabinete-do-pro-reitor/manual-deprocedimentos-contabeis.pdf. Acesso em: 05 jan. 2020 .

IFPB. Manual de rotinas de patrimônio. 2016. Disponível em: http://www.ifpb.edu.br/praf/patrimonio/docume ntos-e-manuais/manual-de-patrimonio-doifpb.pdf. Acesso em: 05 jan. 2020

IFPB. Sistema Suap IFPB. 2020. Disponível em: https://suap.ifpb.edu.br/accounts/login/?next=/. Acesso em: 05 jan. 2020. 
IFPB. Resolução $\mathrm{n}^{\circ} 246$, de 18 de dezembro de 2015. Dispõe sobre o Estatuto do Instituto Federal de Educação, Ciência e Tecnologia da Paraíba, nos termos da legislação em vigor. Disponível em:file://C:/Users/Germana/Downloads/Estatut o\%20do\%20IFPB.pdf. Acesso em: 05 jan. 2020.

IFPB. Resolução Ad Referendum n ${ }^{\circ} 31$, de 16 de julho de 2018. Dispõe sobre o Código de Conduta Ética dos servidores do Instituto Federal de Educação, Ciência e Tecnologia da Paraíba. Disponível em: http://www.ifpb.edu.br/orgaoscolegiados/consu per/resolucoes/2018/ad-referendum/resolucaono-31/view. Acesso em: 05 jan. 2020.

IFPB. Resolução n ${ }^{\circ}$ 65, de 27 de março de 2015. Dispõe sobre a aprovação do Regimento Interno da Ouvidoria Geral do Instituto Federal de Educação, Ciência e Tecnologia da Paraíba. Disponível em: https://www.ifpb.edu.br/orgaoscolegiados/consu per/resolucoes/2015/resolucao-no-65/view. Acesso em: 05 jan. 2020.

IFPB. Acórdão TCU 2.297/2005. 2005. Disponível em: http://www.dados.gov.br/dataset/dadosreferentes-ao-acordao-tcu-n-2-267-2015. Acesso em: 05 jan. 2020.

IFPB. Plano de Desenvolvimento Institucional PDI - 2015/2019. 2015. Disponível em: https://www.ifpb.edu.br/praf/assuntos/document os-praf/area6/plano-de-desenvolvimentoinstitucional-pdi-2015-2019.pdf. Acesso em: 05 jan. 2020.

LARAIA, Roque Barros. Cultura: um conceito antropológico, Zahar, Rio de Janeiro: 2014.

Martínez, José M. Domínguez; RuedA, Nuria. Los indicadores de producción pública. Economistas - Colegio De Madrid, Madrid, $\mathrm{n}^{\circ}$ 105, p. 77-85, jul. 2005.

MATIAS PEREIRA, José. Manual de gestão pública contemporânea. 5. ed. São Paulo: Atlas, 2016.

OLIVEIRA, João Ferreira de. Os papéis sociais e a gestão das universidades federais no Brasil. In: SIMPÓSIO BRASILEIRO DE POLÍTICA E ADMINISTRAÇÃO DA EDUCAÇÃO, 26. 2013, Recife. Anais..., Recife: ANPAE, 2013, p. $1-14$.
OliveIRA, Rodrigo Vieira de; AleXAndrino, Thais de Paula. Do patrimonialismo ao gerencialismo: um breve histórico da administração pública no Brasil. Revista Científica Semana Acadêmica, Fortaleza, n. 174, p. 20-35, jul. 2019. Disponível em: https://semanaacademica.org.br/artigo/dopatrimonialismo-ao-gerencialismo-um-brevehistorico-da-administracao-publica-no-brasil. Acesso em: 20 fev. 2020.

PAGE, Stephen. Measuring accountability for results in interagency collaboratives. Public Administration Review, v. 64, n. 5, p. 591-606, sep./oct. 2004.

Paines, A. T.; Aguiar, M. R. V.; Pinto, N. G. M. A governança no setor público segundo a IFAC: uma análise dos Institutos Federais da região Sul do Brasil. Nucleus, v. 15, n.1, p. 351366, abr. 2018.

PINHEIRO, D. R.; Oliva, E. C. A atuação da auditoria interna na governança pública: um estudo baseado na visão da alta administração das universidades públicas federais brasileiras. Contabilidade Vista \& Revista, [S. 1.], v. 31, n. 2, $2020 . \quad$ Disponível em: https://revistas.face.ufmg.br/index.php/contabili dadevistaerevista/article/view/4933. Acesso em: 29 jul. 2020.

Plataforma Nilo PeÇAnHa (PNP). Rede Federal de Educação Profissional, Científica e Tecnológica Setec/MEC. 2018. Disponível em: http://plataformanilopecanha.mec.gov.br/2018.h tml. Acesso em: 05 jan. 2020.

RoDRIGUES, Miguel Ângelo Vilela. Democracia vs. eficiência: como alcançar equilíbrio em tempo de crise financeira. Rev. Adm. Pública [online], vol.51, n.1, pp.88-104, 2017. ISSN 1982-3134. Disponível em: https://www.scielo.br/pdf/rap/v51n1/00347612-rap-51-01-00088.pdf. Acesso em: 24 ago. 2020 .

SALES, Elana Carla de Albuquerque Silva. Governança no setor público segundo a IFAC: um estudo nas universidades federais brasileiras. 2014. 158 f. Dissertação (Mestrado em Administração e Controladoria) - Universidade Federal do Ceará, Faculdade de Economia, Administração, Atuária e Contabilidade, Fortaleza-CE, 2014.

SCARPIN, Jorge Eduardo; SÖTHE, Ari; KREUZBERG, Fernanda. Custos no setor público: análise dos artigos posteriores à publicação 
estudo $\mathrm{n}^{\circ} 12$ do IFAC. Accounting and Management, v. 6, n. 6, p. 186-201, 2012.

SLOMSKI, et al. Governança corporativa $e$ governança na gestão pública. São Paulo: Atlas, 2008.

\section{Camila Martins de Freitas}

https://orcid.org/0000-0003-4901-027X

Mestre em Educação pelo Programa de Pós-Graduação em Políticas Públicas, Gestão e Avaliação da Educação Superior (MPPGAV/UFPB). Servidora do Instituto Federal de Educação, Ciência e Tecnologia da Paraíba (IFPB).

E-mail: camilamartinscg85@gmail.com

\section{Dimmitre Morant Vieira Gonçalves Pereira}

iD https://orcid.org/0000-0002-9535-7883

Mestre em Ciências Contábeis pelo Programa Multi-institucional e Inter-Regional de PósGraduação em Contabilidade (UnB/UFPE/UFPB/UFRN). Professor do Departamento de Ciências Sociais Aplicadas da Universidade Federal da Paraíba (CCAE/UFPB).

E-mail: dimmitre.morant@academico.ufpb.br

\section{José Jassuipe da Silva Morais}

\section{iD https://orcid.org/0000-0002-6523-142X}

Doutor em Educação pelo PPGE/UFPB e Mestre em Ciências Contábeis pela FVC/BA. Professor do quadro permanente do Programa de Pós-Graduação em Políticas Públicas, Gestão e Avaliação da Educação Superior (MPPGAV) da UFPB e Professor do Departamento de Ciências Sociais Aplicadas da Universidade Federal da Paraíba (CCAE/UFPB).

E-mail: jassuipe@ @otmail.com 